\title{
Predicting of the compressive strength of RCA concrete
}

\author{
Roman Jaskulski ${ }^{1,{ }^{*},}$, Wojciech Kubissa ${ }^{1}$, Peter Koteš $^{2}$, and Miroslav Brodňan ${ }^{2}$ \\ ${ }^{1}$ Warsaw University of Technology, Faculty of Building, Mechanics and Petrochemistry, \\ Łukasiewicza 17, 09-402 Płock, Poland \\ ${ }^{2}$ University of Žilina, Univerzitná 1, 01026 Žilina, Slovakia
}

\begin{abstract}
The paper presents the results of predicting the strength of 61 concretes made with the use of recycled concrete aggregate (RCA). Five models in the form of first-order polynomials containing two to six variables characterizing the composition of the mixture were formulated for this purpose. Factors for unknowns were selected using linear regression in two variants: with and without additional coefficient. For each model, the average absolute error of the concrete strength estimation was determined. Because of the various consequences of underestimation and overestimation of the results, the analysis of models quality was carried out with the distinction of the two cases. The results indicate that the key to improving the quality of models is to take into account the quality of the aggregate expressed by the ACV parameter. Better match results were also obtained for models with more variables and the additional coefficient.
\end{abstract}

\section{Introduction}

Sustainable development is one of the most important contemporary ideas. This term implies a way of managing natural resources that meets current needs without compromising the ability to meet future needs. It assumes a reduction in the exploitation of natural resources for secondary raw materials that have not been re-processed and would have to be stored negatively impacting on the environment. The need to reduce the use of natural resources and energy, reduce greenhouse gas emissions while increasing the capacity to meet needs, affects most areas of life and industry.

The cement industry consumes 20 billion tons of aggregate annually, 1.5 billion tons of cement and 800 million tons of water. It generates $5-7 \%$ of the world's $\mathrm{CO}_{2}$ emissions [1, 2]. It should be assumed that cement and concrete production will continue to increase, so that emissions will also increase. One of the possible ways to reduce the use of natural resources is to use RCA (Recycled Concrete Aggregate) in concrete production. The use of recycled aggregates for the production of concrete can also be a response to the shrinking resources of natural aggregates in many countries and to the rising cost of obtaining them. It should be assumed that RCA will be increasingly used.

*Corresponding author: Roman.Jaskulski@pw.edu.pl 
The use of concrete waste as aggregate is associated with quality requirements. On the other hand, the quality of the aggregate depends primarily on the origin and quality of the concrete from which it was obtained. Numerous researches preceding the introduction of RCA for concrete production have allowed to classify it in terms of quality and to formulate the requirements for their properties to ensure the quality of good concrete $[3,4,5,6]$. The formulation of qualitative requirements for aggregates is to ensure that the RCA used to produce the concrete will not significantly reduce its parameters.

RCA concrete is a relatively new material and, therefore, there are no recognized, proven methods of designing its composition. Taking into account the greater variability of the RCA properties, the higher water demand (due to high absorbability) than in case of natural aggregate and lower strength, the use of traditional concrete mix design methods has limits. With the use of a small amount of RCA of a suitable quality and taking into account in the calculations of additional water absorbed by the aggregate, it is possible to use in the design of mixtures methods which are used in the case of concretes with natural aggregates. While some researchers [7] are of the opinion that even with the replacement of $80 \%$ of natural aggregate with RCA and the associated compressive strength decrease, there is no need to use different mixture design methods as the strength of the concrete can still achieves its assumed values. However, it is still advisable to develop methods to better predict the properties of RCA concrete and to take into account the specificity of this aggregate in designing the composition of the mix.

The research allowed to develop methods of designing RCA concrete considering properties of the aggregate. Some of the methods are based on the aggregate properties determined by the Aggregate Crushing Value (ACV) [4] or the toughness of the aggregate determined in the Los Angeles abrasion test. Also used in such methods is the aggregate resistance to abrasion, denoted as Micro-Deval [8]. The method presented in [4] also includes the $\mathrm{W} / \mathrm{C}$ ratio and the increased water demand of RCA. The authors propose that the concrete mix be designed using the "Three Equations Method" (Bolomey Method) with modified coefficients A. A slightly different approach is presented in [8], where a correction factor is proposed depending on the required concrete strength class and the RCA aggregate quality in relation to the strength of the concrete of the same composition containing only natural aggregate. It was also proposed to use up to $100 \% \mathrm{RCA}$ as a coarse aggregate in concrete of $\mathrm{C} 35 / 45$ strength class or lower when using good quality RCA. The EMV method (Equivalent Mortar Volume) described in [9, 10,11] is based on the assumption that the mortar contained in the RCA should be included in the total amount of mortar in the mix. This method gives good results, however, it requires precise determination of the mortar content in the RCA. In addition, its use may be problematic if various RCA with different mortar content are used.

The neural networks $[12,13]$ are also used for predicting the compressive strength and other properties of RCA concrete. However, they have the disadvantage that a large number of sets of differentiated data are required to properly train the network. Same as later to verify its correctness. This may limit the usefulness of using neural networks in practical applications. In addition, neural networks are much better at classifying data than predicting results based on the data provided [14]. Nevertheless, this does not negate the idea of using this tool in predicting the properties of concrete with RCA or identifying parameters that have a significant effect on these properties.

An interesting approach is to use the Model Tree (MT) algorithm to create decision trees and models for predicting the properties of RCA $[15,16]$ as well as natural aggregates concretes [17]. These algorithms do not require too much detailed data on materials and composition of concrete to create a decision tree to estimate the properties of concrete. Such data can be obtained from the literature and a properly working model can be developed using just over 200 results sets [15]. This is a great advantage of these methods 
due to the generally limited amount of data coming either from own research or from the literature on the composition and properties of both materials and concrete. The assembly of the required number of results in this case is easier than in the case of neural networks.

Another approach to designing or predicting the properties of RCA concrete with most of the advantages of the MT algorithm, but which is even more simplicity, is to build single models based on mix and RCA parameters using linear regression. This is the approach that is the subject of this paper.

The paper presents the results of applying models obtained by linear regression method to predict RCA concrete strength. Models with increasing numbers of two to six parameters are considered. Each model is additionally formulated in two versions. In the first an additional coefficient is used that took into account the influence of parameters not explicitly included in the model. In the second only the parameters were used which values were assumed during the design of the mixture or measured.

\section{Properties of analysed concrete mixtures}

Parameters of sixty concrete mixtures were used to formulate and test the models. In forty of them Portland cement CEM I 32.5R was used and in the rest twenty Portland-fly ash cement CEM II/B-V 32.5N. Both cements were from Ożarów Cement Plant. As a natural aggregate, river sand $0-2 \mathrm{~mm}$ and pebble gravel $2-16 \mathrm{~mm}$ were used.

RCA in the first forty series was prepared from the remaining specimens after the compressive strength tests made of 11 concretes with varying strengths ranging from 10 to $50 \mathrm{MPa}$. Concrete at the time of crushing had a minimum of 90 days. Aggregate obtained from these concretes had an average ACV ranging from 16.5 to 25.1.

The RCA in the remaining twenty one series was obtained from similar specimens of concrete of strength classes from $\mathrm{C} 25 / 30$ to $\mathrm{C} 50 / 60$, which were crushed after 1 year to 4 years after preparing. The aggregate during the preparation was mixed several times, thus its properties have averaged. The average value of ACV of this aggregate was 17.3. Concrete specimens were crushed in a laboratory jaw crusher and were sieved to obtain a fraction of $4-16 \mathrm{~mm}$. The fraction below $4 \mathrm{~mm}$, due to the large amount of dust and cement paste and associated with it very high water demand, was not used.

The mixes were prepared in a 250-liter free-fall concrete mixer. Tap water was used as the mixing water. The ingredients were dosed with the accuracy required by EN 206. Table 1 gives the limit values of the compressive strength of the concrete obtained in the tests and other parameters characterizing the blends taken into account in the presented models.

Table 1. Limit values of selected parameters of analysed concrete mixtures

\begin{tabular}{|l|c|c|c|c|c|c|c|c|}
\hline Parameter & $\begin{array}{c}\mathbf{f}_{\mathbf{c m}} \\
{[\mathbf{M P a}]}\end{array}$ & $\begin{array}{c}\mathbf{W} / \mathbf{C} \\
{[-]}\end{array}$ & $\mathbf{C}$ & $\mathbf{W}$ & $\begin{array}{c}\text { FA/TA } \\
{[-]}\end{array}$ & $\begin{array}{c}\text { ACV } \\
{[\mathbf{\%}]}\end{array}$ & $\begin{array}{c}\mathbf{C A} / \mathbf{C} \\
{[-]}\end{array}$ & $\begin{array}{c}\mathbf{r} \\
{[-]}\end{array}$ \\
\hline Maximum value & 62.6 & 1.0 & 540 & 261 & 0.43 & 25.1 & 6.47 & 1.0 \\
\hline Minimum value & 14.6 & 0.4 & 200 & 111 & 0.30 & 12.1 & 1.92 & 0.5 \\
\hline
\end{tabular}

\section{Models}

The analysed models were based on selected parameters such as: content of cement $\mathrm{C}$, the effective water content $\mathrm{W}_{\text {eff }}$, taking into account the amount of water absorbed by RCA, the proportion of fine aggregate to total aggregate mass FA/TA, the proportion of coarse aggregate to cement $\mathrm{CA} / \mathrm{C}$, the $\mathrm{ACV}$ value and volumetric share of RCA in total aggregate volume $\mathrm{r}$ calculated according to formula (1) where $M$ is the weight of natural (index NA) 
and recycling (index RA) aggregate in $1 \mathrm{~m}^{3}$ of concrete, and $S S D$ is the density of aggregate in dry state.

$$
r=\frac{\frac{M_{R A}}{S S D_{R A}}}{\frac{M_{R A}}{S S D_{R A}}+\frac{M_{N A}}{S S D_{N A}}} \cdot 100 \%
$$

Each model has the form of a polynomial, the sum of the aforementioned parameters multiplied by the coefficients expressing their influence on the final result. Models differ in the number of parameters included (from 2 to 6 ) and the presence of a additional coefficient that expresses the influence of unknown or unidentifiable parameters. All possible combinations of parameters used in the model were not analyzed, but the output model containing only two of them (water and cement content) was expanded sequentially by the selected additional parameters. The general form of the models is presented below in the form of the general formula (2) in the case of models without additional coefficient and in formula (3) in the case of models with additional coefficient.

$$
\begin{gathered}
f_{c m, 1}=m_{1} C+m_{2} W_{e f f}+m_{3} \frac{F A}{T A}+m_{4} \frac{C A}{C}+m_{5} A C V+m_{6} r \\
f_{c m, 2}=m_{1} C+m_{2} W_{e f f}+m_{3} \frac{F A}{T A}+m_{4} \frac{C A}{C}+m_{5} A C V+m_{6} r+\mathrm{m}
\end{gathered}
$$

\section{Results and discussion}

The coefficients in the models were calculated by linear regression based on parameters of 46 concrete mixtures with RCA blends. Table 2 summarizes the obtained parameters.

Table 2. Values of the models coefficients

\begin{tabular}{|c|c|c|c|c|c|c|c|c|}
\hline \multirow{2}{*}{$\begin{array}{c}\text { Number } \\
\text { of } \\
\text { variables }\end{array}$} & $\mathbf{m}_{\mathbf{1}}$ & $\mathbf{m}_{\mathbf{2}}$ & $\mathbf{m}_{\mathbf{3}}$ & $\mathbf{m}_{\mathbf{4}}$ & $\mathbf{m}_{\mathbf{5}}$ & $\mathbf{m}_{\mathbf{6}}$ & $\mathbf{m}$ \\
\cline { 2 - 8 } & \multicolumn{7}{|c|}{ models without the additional coefficient } \\
\hline 2 & 0.137 & -0.071 & 0 & 0 & 0 & 0 & --- \\
\hline 3 & 0.149 & -0.291 & 98.8 & 0 & 0 & 0 & --- \\
\hline 4 & 0.161 & -0.311 & -118.5 & -0.416 & 0 & 0 & --- \\
\hline 5 & 0.201 & -0.278 & 33.4 & -0.69 & 4.13 & 0 & --- \\
\hline 6 & 0.175 & -0.214 & 30.5 & -1.66 & 3.16 & 23.6 & --- \\
\hline & & models with the additional coefficient & & \\
\hline 2 & 0.134 & -0.259 & 0 & 0 & 0 & 0 & 34.5 \\
\hline 3 & 0.135 & -0.263 & 5.54 & 0 & 0 & 0 & 32.9 \\
\hline 4 & 0.147 & -0.280 & -42.9 & -0.935 & 0 & 0 & 65.7 \\
\hline 5 & 0.114 & -0.286 & -68.2 & -1.02 & -2.64 & 0 & 98.0 \\
\hline 6 & 0.104 & -0.237 & -60.4 & -1.72 & -2.70 & 17.8 & 88.4 \\
\hline
\end{tabular}

The models thus obtained were then tested with use of the parameters of the following 15 mixtures. Several parameters were calculated to determine the quality of the models. 
The basis for the model quality assessment was the difference between the compressive strength values obtained from the test and predicted on the basis of models. As the average error, the mean of these differences was calculated regarding their sign.

Due to the fact that the underestimation of the compressive strength of the concrete is an error in favor for the safety of the structure made of such a material, as opposed to the overestimation of this value, further evaluation of the two cases was made. A positive average error was calculated on the basis of differences greater than zero (cases of model underestimation) and the negative average error on the basis of the values of differences smaller than zero (cases of overestimation). The determination coefficient $\mathrm{R}^{2}$ that determines the quality of the model's fit to the results was also calculated. The values obtained are given in Table 3 (models without the additional coefficient) and in Table 4 (models with the additional coefficient). In the above mentioned tables also values of the maximum positive and negative error for each model were included.

Table 3. Values of the parameters in the models without the additional coefficient

\begin{tabular}{|c|c|c|c|c|c|c|}
\hline \multirow{2}{*}{$\begin{array}{c}\text { Model quality } \\
\text { assesment parameter }\end{array}$} & \multicolumn{5}{c|}{ Number of the variables in the model } \\
\cline { 2 - 7 } & $\mathbf{2}$ & $\mathbf{3}$ & $\mathbf{4}$ & $\mathbf{5}$ & $\mathbf{6}$ \\
\hline \multirow{3}{*}{$\begin{array}{c}\text { average error } \\
{[\mathrm{MPa}]}\end{array}$} & general & -0.22 & -0.40 & -0.07 & -2.02 & -1.56 \\
\cline { 2 - 7 } & positive & 4.88 & 7.86 & 4.26 & 2.78 & 4.49 \\
\cline { 2 - 7 } & negative & -6.05 & -7.63 & -6.58 & -5.22 & -3.75 \\
\hline $\begin{array}{c}\text { maximum error } \\
{[\mathrm{MPa}]}\end{array}$ & positive & 8.00 & 16.49 & 7.35 & 5.41 & 7.70 \\
\cline { 2 - 8 } & negative & -14.69 & -20.95 & -12.78 & -11.95 & -11.93 \\
\hline \multicolumn{2}{c}{ coefficient of determination $\mathrm{R}^{2}[--]$} & 0.45 & 0.64 & 0.67 & 0.81 & 0.89 \\
\hline
\end{tabular}

Table 4. Values of the parameters in the models with the additional coefficient

\begin{tabular}{|c|c|c|c|c|c|c|}
\hline \multirow{2}{*}{$\begin{array}{c}\text { Model quality } \\
\text { assesment parameter }\end{array}$} & \multicolumn{5}{|c|}{ Number of the variables in the model } \\
\cline { 2 - 7 } & $\mathbf{2}$ & $\mathbf{3}$ & $\mathbf{4}$ & $\mathbf{5}$ & $\mathbf{6}$ \\
\hline \multirow{3}{*}{$\begin{array}{c}\text { average error } \\
{[\mathrm{MPa}]}\end{array}$} & general & -1.59 & -1.66 & -2.63 & -2.65 & -0.81 \\
\cline { 2 - 7 } & positive & 4.30 & 4.24 & 2.50 & 1.55 & 3.36 \\
\cline { 2 - 7 } & negative & -5.52 & -5.59 & -3.91 & -4.17 & -3.60 \\
\hline $\begin{array}{c}\text { maximum error } \\
{[\mathrm{MPa}]}\end{array}$ & positive & 6.31 & 6.17 & 3.07 & 2.56 & 8.77 \\
\cline { 2 - 7 } & negative & -13.70 & -13.72 & -8.40 & -6.77 & -1.25 \\
\hline \multicolumn{2}{c|}{ coefficient of determination $\mathrm{R}^{2}[--]$} & 0.74 & 0.74 & 0.92 & 0.93 & 0.97 \\
\hline
\end{tabular}

As it can be seen, in case of models without the additional coefficient the average error values are not forming any clear trends. The lowest general average error was obtained for the model with four parameters, the lowest average positive error for the model with five variables and the lowest average negative error for the model with six parameters. The best fit for these models expressed by the $\mathrm{R}^{2}$ value was obtained for the model with the maximum number of parameters.

If results for models with the additional coefficient are analyzed, the situation is a little more clear. The lowest values of the average general and negative errors and the lowest maximum value of the negative error were obtained for the model with six parameters. The 
lowest value of the average positive error and the lowest maximum value of the error were obtained for the model with five parameters. The quality of the models' fit is growing with the increasing number of parameters included in the model formula. And the values of the $\mathrm{R}^{2}$ determination coefficient are clearly higher for these models than for models without the additional coefficient.

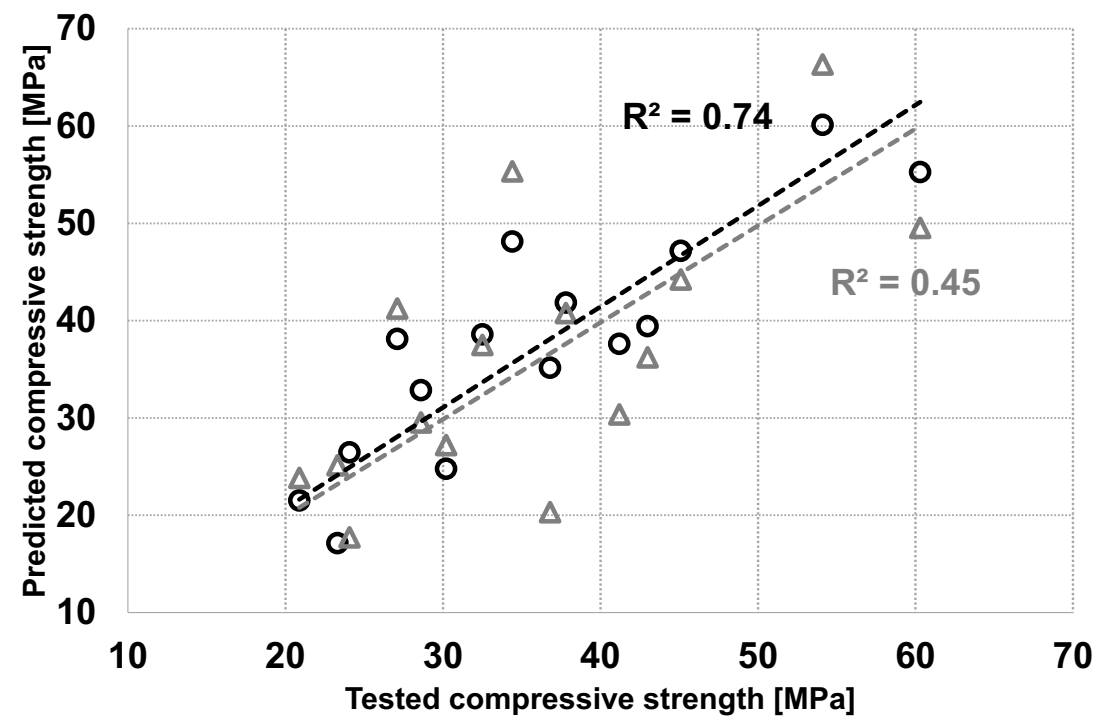

Fig. 1. Comparison of the concrete compressive strength values obtained from tests and predicted by models with two parameters: black - model with the additional coefficient, grey - model without the additional parameter.

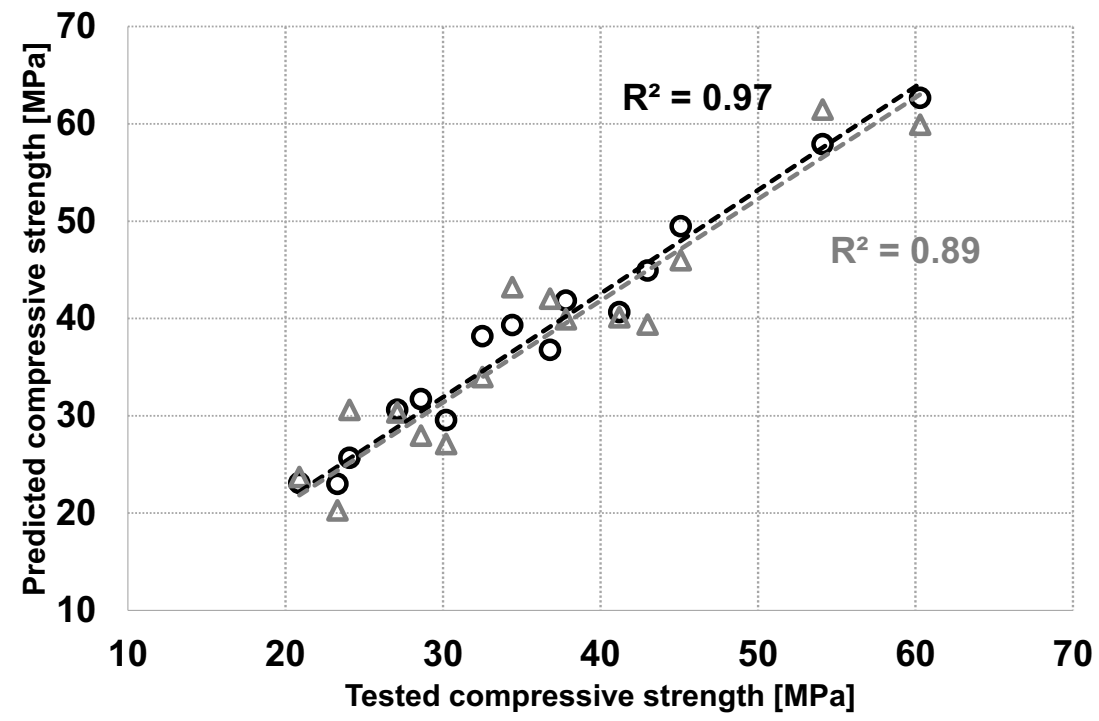

Fig. 2. Comparison of the concrete compressive strength values obtained from tests and predicted by models with six parameters: black - model with the additional coefficient, grey - model without the additional parameter. 
The differences between two regarded kinds of models are also presented graphically in the Figures 1 and 2. In both the figures regression lines are presented, the black line for model with the additional coefficient and the grey one for the model without it. In the Figure 1 models with two parameters are compared and the value of determination coefficient for both cases are presented. In the Figure 2 in the same way two models with the maximum number of parameters are compared. It can be clearly seen, that the models with six parameters better predict the values of the compressive strength of concretes with RCA than models with only two parameters. In the first case the results are less scattered around the regression line.

\section{Summary and conclusions}

The calculations and analyses of the formulated predictive models allowed to formulate the following conclusions.

It seems possible to formulate a model that allows to estimate the compressive strength of RCA concretes using the linear regression method with satisfactory accuracy. The models obtained by this method allow for proper adjustment measured by the determination coefficient $\mathrm{R}^{2}$, of the RCA concrete compressive strength calculated values to the values obtained from the strength test,. The quality of the fit increases with increasing number of parameters taken into account. Similarly, it is preferable to include an additional parameter that takes into account the effects of unknown or unmeasured variables. It seems that it can express, for example, the effect of the type of cement used in the concrete from which the RCA was obtained or the coefficient w/c of the concrete. Such parameters are usually difficult or even impossible to determine, but it cannot be assumed that these factors do not affect the strength of RCA concrete.

The question that remains to be clarified is the value of this additional parameter. Should this be a value taken straight from the calculations by means of linear regression, which maximizes the quality of matching results to the model? Or should it be additionally adjusted arbitrarily to minimize the risk of overestimate of the strength value? This may be one of the areas of further consideration and development of the topic.

But that is not the only question that remains open. Analysis of estimation errors calculated for each model indicates, unlike fit quality analysis, that adding additional variables does not necessarily lead to error reduction. It is worth to find in this situation the answer to the question, which of the parameters included allow to minimize errors, especially in cases where the model overestimates the value of strength. For this purpose, it is worthwhile to carry out an analysis of models containing different combinations of variables already taken into account, but also those that have not been included (e.g. aggregate water absorbability, its porosity, etc.).

The authors also see the need to formulate models at a higher level of generality based on dimensionless variables. It would be useful to adopt some technologically justified limit values for the variables involved, then to standardize (in a statistical sense) the data to the models using those limits, and then to formulate the models in new form based on such data. In summary, the problem presented in the paper can certainly not be considered solved, but the results presented are quite a big step towards such a solution.

\section{References}

1. L. Czarnecki, M. Kapron, Int. Jour. of the Soc. of Mat. Engin. for Res. 17, 99 (2010)

2. L. Czarnecki, W. Kurdowski, Budown., Technol., Archit., 37, 50 (2007) 
3. M.N. Fardis (Ed.), Innovative materials and techniques in concrete construction. ACES Workshop, (Springer Netherlands, Dordrecht, 2012)

4. A. Koper, M. Koper, W. Kubissa. Key Engin. Mater. 677, 266 (2016)

5. W. Kubissa, R. Jaskulski, A. Koper, M. Supera, Key Engin. Mater. 677, 233 (2016)

6. RILEM TC 121-DRG, Mater. and Struct., 173, 557 (1994)

7. W.H. Kwan, M. Ramli, K.J. Kam, M.Z. Sulieman, Constr. and Build. Mater. 26, 565 (2012)

8. T. Kausay, T. Simon, G. Balázs, Concr. Struct, 9, 45 (2008)

9. A. Abbas, G. Fathifazl, O.B. Isgor, A.G. Razaqpur, B. Fournier, S. Foo, Cem. and Concr. Comp. 31, 555 (2009)

10. G. Fathifazl, A. Abbas, A.G. Razaqpur, O.B. Isgor, B. Fournier, F. Simon, J. of Mater. in C. Engin. 21, 601 (2009)

11. C. Jiménez, M. Barra, S. Valls, D.F. Aponte, E. Vázquez, Mater. de Constr. 313, e006 (2014)

12. A. Dantas Trocoli Abdon, M. Batista Leite, K. de Jesus Nagahama, Construction and Building Materials 38, 717 (2013)

13. N. Deshpande, S. Londhe, S. Kulkarni, Intern. J. of Sust. Built Env. 3, 187 (2014)

14. R. Tadeusiewicz, Elementarne wprowadzenie do techniki sieci neuronowych $z$ przykładowymi programami (Akademicka Oficyna Wydawnicza PLJ, Warszawa,1998)

15. A. Behnood, J. Olek, M.A. Glinicki, Proceedings of 11th International Symposium on Brittle Matrix Composites 2015, 381 (2015)

16. A. Behnood, J. Olek, M.A. Glinicki, Constr. and Build. Mater. 94, 137 (2015)

17. C. Deepa C., K. SathiyaKumari, V. Pream Sudha, Int. J. of Comp. App. 6, 18 (2010) 